\title{
Acoustic Performance of Parallel Baffled Silencers Different Configurations in HVAC Channel
}

\author{
Antonio Petosic, Sanja Grubesa, Mia Suhanek*, Ivan Djurek \\ Department of Electroacoustics, Faculty of EE and Computing, University of Zagreb, Zagreb, Croatia
}

Email address:

mia.suhanek@fer.hr (M. Suhanek)

${ }^{*}$ Corresponding author

To cite this article:

Antonio Petosic, Sanja Grubesa, Mia Suhanek, Ivan Djurek. Acoustic Performance of Parallel Baffled Silencers Different Configurations in HVAC Channel. Engineering and Applied Sciences. Vol. 3, No. 3, 2018, pp. 88-96. doi: 10.11648/j.eas.20180303.14

Received: August 27, 2018; Accepted: September 7, 2018; Published: October 27, 2018

\begin{abstract}
Serious noise pollution is one of the most unwanted consequences of the rapid urbanization and industrialization and various studies have shown that long exposure to noise can result in different health issues. Therefore, the performance of large industrial baffled silencer is crucial for reducing the environmental noise from large industrial plants. In this particular research the acoustic parameters of several different configurations of parallel baffled silencers have been compared by using an in-situ measurement method according to the ISO-11820:1996 Standard. The geometrical parameters e.g. length, thickness and distance between baffles as well as the absorption parameters of baffles have been changed in terms of full absorption and half-absorption surface. Furthermore, their influence on the silencer performance in channel with and without flow has been measured. Transmission and insertion loss acoustic parameters in octave frequency bands from $63 \mathrm{~Hz}$ up to $16 \mathrm{kHz}$ are determined in the in-situ measurement setup including the influence of the reflections from baffles at the inlet side and opening at the outlet side. Moreover, the analytical expression (Piening and trapezoidal equation) for one parallel baffled silencer's configuration has been compared with the measurement values on octave bands of interest. Additionally, the sound pressure distribution between baffles has also been measured and it can be concluded that the sound pressure level change is much larger at the beginning when compared to the value at the end of a silencer.
\end{abstract}

Keywords: Parallel Baffled Silencers, Insertion Loss, Transmission Loss, Artificial Sound Source, Real Sound Source

\section{Introduction}

The performance of large industrial baffled silencer is very important for reducing the environmental noise from large industrial plants. Their performance is measured by using international standards describing in-situ measurement conditions [1] and laboratory conditions [2]. The performance of the silencer can be modelled by using empirical equations which rarely include all effects having influence on their performance [3-6] or more precise numerical methods [7-10]. Regarding the experimental, analytical and numerical methods to determine the acoustic properties of parallel baffled silencers there is no direct comparison of the acoustical performance between same silencers with different length, thickness of baffles and distance between baffles and types of silencer with same dimensions when absorption properties are changed by adding reflective baffles instead of absorptive.

There is also no available data about performance of silencers regarding the increasing the length or putting small gap between baffles in the direction of sound propagation through the HVAC channel.

Regarding the in-situ and laboratory setups for measurements, we have decided to use less complicated in-situ measurement setup [1] as closest to the real operating conditions when these types of silencers are installed at the outlet of HVAC chamber.

The laboratory measurement setup [2] is more complicated and characterized by measuring the limiting insertion loss of the measurement setup and reflection coefficients from anechoic termination of channel and by checking maximum level differences for three microphone positions of measured sound pressure levels before and after the silencers and substitution elements [2]. Due to these reasons there is a difference between IL and TL in in-situ measurement setup. 
In addition to the measurements of parameters in standard with artificial and real sound source we have measured the sound pressure distributions in empty channel and between baffles in side and middle positions.

\section{Theoretical Background}

The acoustical parameters measured are Insertion Loss (IL) and Transmission Loss $(T L)$. Insertion loss for sound pressure level is defined as sound pressure difference on the receiving side (point or small surface to avoid influence of non-diffuse sound field) of measurement setup when silencer is not installed and when the silencer is installed. The insertion loss for sound pressure level is defined with Eq. $1[1,2]$.

$$
D_{i p s}=L_{p I I}-L_{p I},
$$

where $L_{p I I}$ save raged sound pressure level without silencer and $L_{p I}$ is averaged sound pressure level with silencer.

The insertion loss for sound power level $\left(D_{i s}\right)$ is the same as calculated insertion loss for the sound pressure level because the measurement surface for calculating sound power from sound pressure (intensity) is the same (outlet channel or surface after opening).

TL is defined as reduction of the sound power through the test object as difference of sound power level before and after the silencer (in inlet and outlet duct for this measurement setup) [1].

The transmission loss of sound pressure level is defined as difference of the averaged pressure levels measured at the source side $\left(\overline{L_{p 2}}\right.$ - in channel) and on the measurement surface on the receiving side (in room, without diffuse field in our situations) (Eq. 2)

$$
D_{t s}=L_{w 2}-L_{w 1} \text {. }
$$

Transmission loss for sound power level is determined from sound pressure levels and by knowing the surface where the sound pressure levels are averaged (sound pressure levels are transformed into intensity and intensity into acoustic power). The additional correction terms $\left(K_{l}\right.$, $K_{2}$ ) in some cases should be added to calculations due to corrections for different type of sound fields and influence of the reflections at silencer entrance and outlet of the channel due to reflections (Eq. 3) [1]

$$
D_{t s}=L_{w 2}-L_{w 1} \text {. }
$$

The sound power level at receiver side is calculated by using Eq. 4

$$
L_{w 1}=\bar{L}_{p 1}+10 \cdot \lg \frac{S_{1}}{S_{0}}+K_{1} .
$$

The sound power level at source side is calculated by using Eq. 5

$$
L_{w 2}=\bar{L}_{p 2}+10 \cdot \lg \frac{S_{2}}{S_{0}}+K_{2} .
$$

where $S_{1}$ is surface on the receiving side and $S_{2}$ is the surface on the transmission side. The sound power levels are determined from averaged sound pressure levels assuming that sound intensity and pressure are connected via measurement surface and using plane wave relation for fundamental propagation mode. This cause some errors in estimation of parameters because this approximation is valid under cut-off frequency.

According to the Standard ISO 7235:2009 [2] the Insertion loss and Transmission loss are identical but in in-situ measurement situations according [1] when there are no modal filters between source of sound and tested object and anechoic termination at the end of channel which reduces reflection from the end of the channel back in the channel.

\section{Materials and Measurement Setups}

First all parameters of baffles have been considered and then the measurement setup is analyzed.

\subsection{Parameters of Baffles}

The geometrical parameters having influence on the silencers performance are given in Table 1 . In addition of changing geometrical parameters the reflective sheet $(2 \mathrm{~mm}$ thickness) is added on the half of the absorptive side.

Table 1. Geometrical parameters of measured parallel baffled silencers.

\begin{tabular}{lllll}
\hline Length (L) $[\mathbf{m m}]$ & $\mathbf{5 0 0}$ & $\mathbf{1 4 0 0}$ & $\mathbf{2 0 0 0}$ & - \\
\hline Thickness (d) $[\mathrm{mm}]$ & 100 & 200 & 300 & - \\
Gap between baffles (s) $[\mathrm{mm}]$ & 50 & 75 & 100 & 200 \\
\hline
\end{tabular}

The baffles can have two total absorptive sides (full absorption - A) and partially reflective sides (half of the surfaces on the two side-opposite orientation). The weight data for baffles are given in Table 2 .

Table 2. Mass of absorptive baffles.

\begin{tabular}{llll}
\hline Thickness/Length & L=500 $\mathbf{~ m m}$ & L=1400 $\mathbf{~ m m}$ & L=2000 $\mathbf{~ m m}$ \\
\hline $\mathrm{d}=100 \mathrm{~mm}$ & $4.2 \mathrm{~kg}$ & $9.8 \mathrm{~kg}$ & $13 \mathrm{~kg}$ \\
$\mathrm{~d}=200 \mathrm{~mm}$ & $7.8 \mathrm{~kg}$ & $18.2 \mathrm{~kg}$ & $19.4 \mathrm{~kg}$ \\
$\mathrm{~d}=300 \mathrm{~mm}$ & $11.4 \mathrm{~kg}$ & $27 \mathrm{~kg}$ & $36.8 \mathrm{~kg}$ \\
\hline
\end{tabular}

Table 3. Mass of semi-reflective baffles.

\begin{tabular}{llll}
\hline Thickness/Length & $\mathbf{L}=\mathbf{5 0 0}$ & $\mathbf{L}=\mathbf{1 4 0 0}$ & $\mathbf{L}=\mathbf{2 0 0 0}$ \\
\hline $\mathrm{d}=100$ & $6.8 \mathrm{~kg}$ & $17.4 \mathrm{~kg}$ & $22.6 \mathrm{~kg}$ \\
$\mathrm{~d}=200$ & $10.6 \mathrm{~kg}$ & $26 \mathrm{~kg}$ & $37.4 \mathrm{~kg}$ \\
$\mathrm{~d}=300$ & $13.8 \mathrm{~kg}$ & $34.8 \mathrm{~kg}$ & $48 \mathrm{~kg}$ \\
\hline
\end{tabular}

The acoustic parameters (absorption coefficient) of mineral rock wool (thickness $50 \mathrm{~mm}$ and density $50 \mathrm{~kg} / \mathrm{m}^{3}$ ) which fills the baffles are given in Table 1-4. The full name of material is KNAUF INSULATION MCH B D5 (GVB / GW).

Table 4. Absorption coefficient of mineral glass wool.

\begin{tabular}{lllllll}
\hline $\mathbf{f}[\mathbf{H z}]$ & $\mathbf{1 2 5}$ & $\mathbf{2 5 0}$ & $\mathbf{5 0 0}$ & $\mathbf{1 0 0 0}$ & $\mathbf{2 0 0 0}$ & $\mathbf{4 0 0 0}$ \\
\hline$\alpha-50 \mathrm{~mm}$ & 0.2 & 0.6 & 0.95 & 1.0 & 1.0 & 0.95 \\
\hline
\end{tabular}

The open area ratio (OAR) in channel has been calculated 
for each parallel baffled silencer configuration and it is given in the Table 5. The open area is the area available for gas or air flow through the silencer.

Table 5. Open area ratio $(O A R)$ depending on the different parallel baffled silencer configuration.

\begin{tabular}{lll}
\hline Thickness & Air space & OAR [\%] \\
\hline$d=100$ & $\mathrm{~s}=50$ & 34.7 \\
$\mathrm{~d}=100$ & $\mathrm{~s}=75$ & 42.7 \\
$\mathrm{~d}=100$ & $\mathrm{~s}=100$ & 51 \\
$\mathrm{~d}=200$ & $\mathrm{~s}=75$ & 34.7 \\
$\mathrm{~d}=200$ & $\mathrm{~s}=100$ & 34.7 \\
$\mathrm{~d}=200$ & $\mathrm{~s}=125$ & 34.7 \\
$\mathrm{~d}=200$ & $\mathrm{~s}=200$ & 51 \\
$\mathrm{~d}=300$ & $\mathrm{~s}=100$ & 26.5 \\
$\mathrm{~d}=300$ & $\mathrm{~s}=200$ & 51 \\
\hline
\end{tabular}

\subsection{Measurement Setups}

Broadband pink noise is generated with artificial sound source (without flow) for all configurations and with real source in some silencer configurations (uniaxial fan with flow speed of $2.3 \mathrm{~m} / \mathrm{s}$ in duct) and sound pressure levels (SPL) are measured in duct in front of the silencer), in the duct after silencer (receiving side 2) and in room without diffuse field (receiving side 1), behind the installed silencer in channel as proposed in ISO 11820:1996 [1] for in-situ operating conditions. There are number of possible situations (but due to restrictions the chosen measurement setup is shown in Figure 1. The width and height of the empty channel where baffles are located are $L_{\mathrm{x}}=1325 \mathrm{~mm}$ and $L_{\mathrm{y}}=1025 \mathrm{~mm}$.

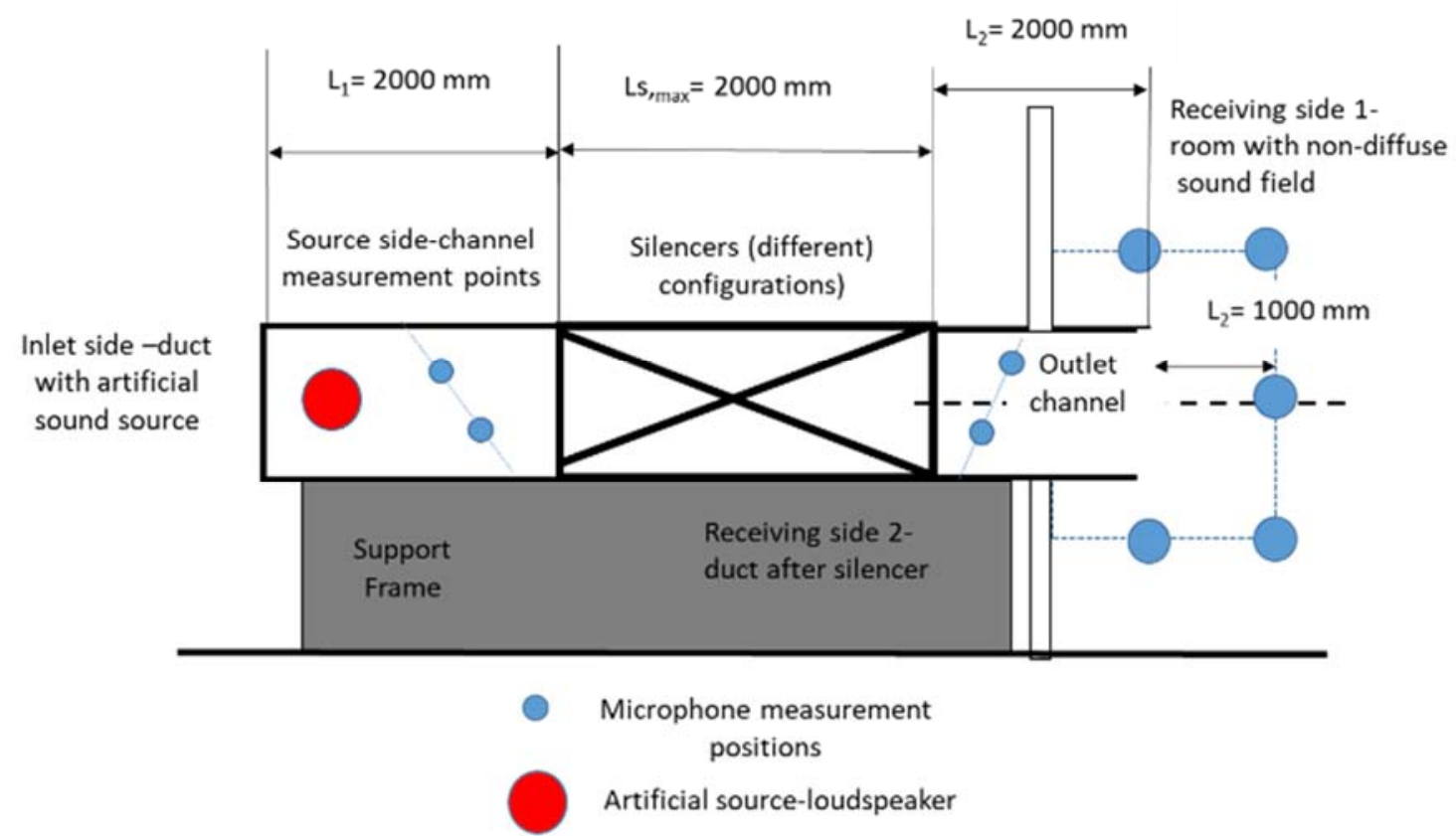

Figure 1. Measurement setup according ISO 11820:1996 chosen for the considered situation.

In addition to receiving measurement points on the surface in the room with non-diffuse sound field, additional points are chosen in the duct after silencer to see the difference between results for measured parameters due to reflection on the channel end and due to additional losses in the channel due to propagation. It is observed that there was no significant difference between results for acoustic parameters obtained in the channel as receiving side and on the receiving side in the room with non-diffuse sound field.

The source side is also tested to see the influence of the reflections at the silencer on the estimation of the input sound power level. In addition to measurements of SPL before silencer additional measurements are done in empty channel when silencer is not installed.

\subsection{Possible Effects on the Measurement Results in In-Situ Conditions}

First, we considered the resonance frequencies of empty channel where the baffles of different length are located as in
Figure 1 . The partially one end closed channel was chosen to simulate in-situ conditions with real source in the air handling unit. The appropriate length is chosen to scale down the resonance frequencies of empty channel below the frequency range of interest.

A resonance frequency of closed channel at one end as shown in Figure 1 is defined with Eq. 6, were $c$ is speed of sound in air $c=343 \mathrm{~m} / \mathrm{s}, L$ is the total length of the channel and is $n$ is an odd number $(1,3,5 \ldots)$ representing the resonance mode of interest.

$$
f_{n}=n \cdot \frac{c}{4 L}
$$

The several resonance frequencies of measurement system for empty channel closed at one end are shown in Table 6.

Table 6. The resonant frequencies of the channel.

\begin{tabular}{llllll}
\hline $\mathbf{n}$ & $\mathbf{1}$ & $\mathbf{3}$ & $\mathbf{5}$ & $\mathbf{7}$ & $\mathbf{9}$ \\
\hline $\mathrm{f}_{\mathrm{n}}[\mathrm{Hz}]$ & 14.3 & 42.9 & 71.5 & 100.1 & 128.7 \\
\hline
\end{tabular}


A cut off frequency of channel for plane and higher modes of propagation is defined with Eq. 7, were $c$ is speed of sound in air, $L_{x}$ is $L_{y}$ are the dimensions of the channel see Figure 1. and $m$ and $n$ are nonnegative integers that cannot all be zero.

$$
f_{c n}=\frac{c}{2} \sqrt{\frac{m^{2}}{L_{x}^{2}}+\frac{n^{2}}{L_{y}^{2}}}
$$

The results for cut-off frequencies are shown in Table 7.

Table 7. Cut off frequency of channel for different modes

\begin{tabular}{lllll}
\hline $\mathbf{n}$ & $\mathbf{1}$ & $\mathbf{0}$ & $\mathbf{1}$ & $\mathbf{2}$ \\
\hline $\mathrm{m}$ & 0 & 1 & 1 & 0 \\
$\mathrm{f}_{\text {cut-off }}[\mathrm{Hz}]$ & 140 & 185.4 & 232.3 & 280 \\
\hline
\end{tabular}

\section{Measurement Results}

The large number of measurement configurations has been considered and the results for several are compared here in this paper.

\subsection{TL and IL Parameters}

Firstly, we show the results obtained for measurement configuration with absorptive baffles surface and we have compared the $I L$ and $T L$ parameters for the same configuration.
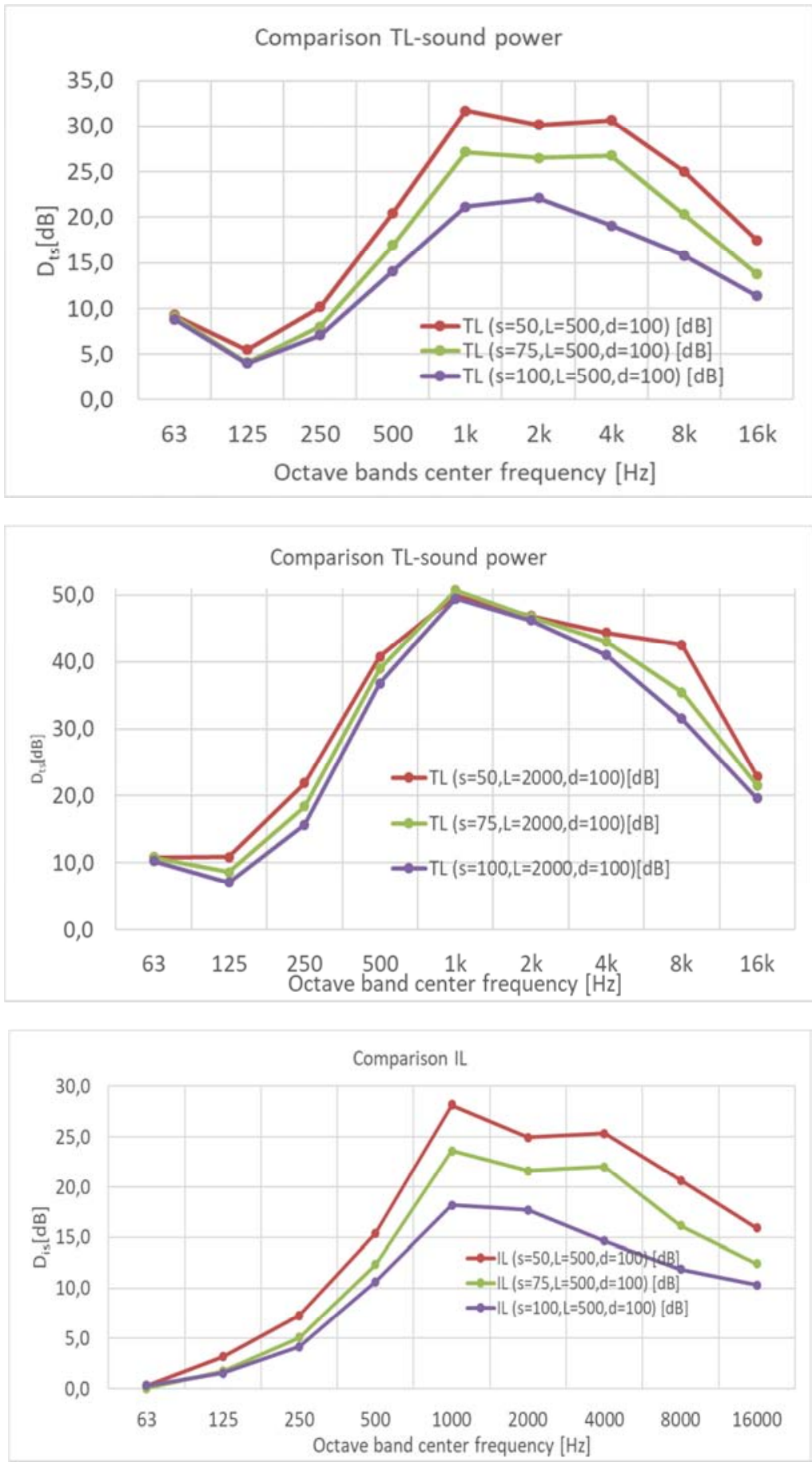


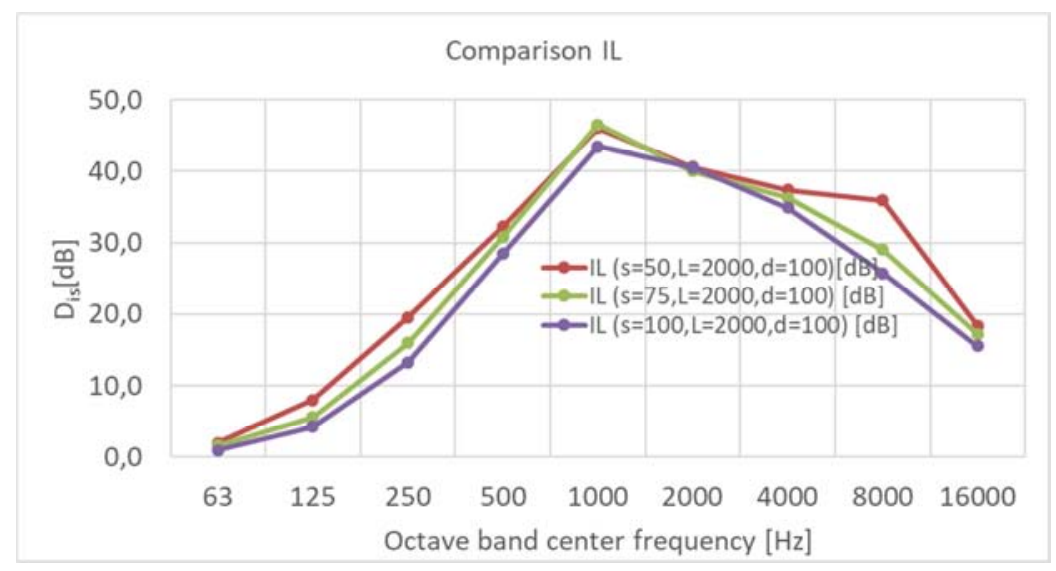

Figure 2. Comparison between TL and IL parameters for absorptive baffles with given thickness, $d$, space s and length $L$.

It is evident that $T L$ and $I L$ parameter are not the same as in laboratory configurations due to reflections from baffles and anechoic termination having influence on the results when $T L$ parameter is considered (see Figure 3.).

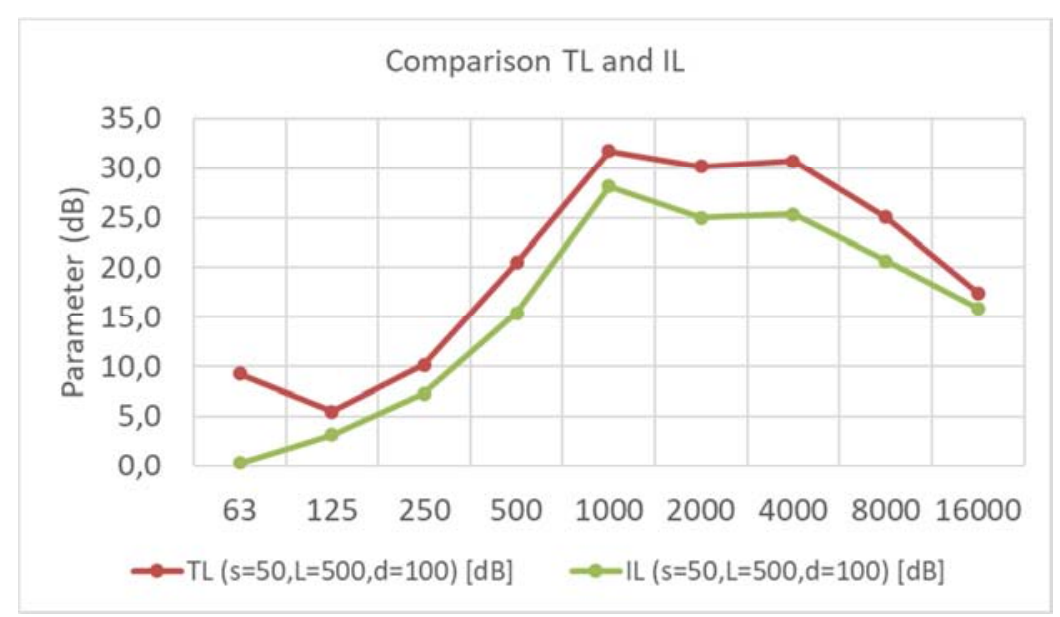

Figure 3. Comparison between TL and IL parameter for the same configuration.

This can be avoided by using laboratory setup when additional elements are used in measurement channel.

\subsection{Comparison Between Full Absorptive and Semi Reflective Baffles}

The comparison in performance between full absorptive and semi-reflective baffles is shown in Figure 4.

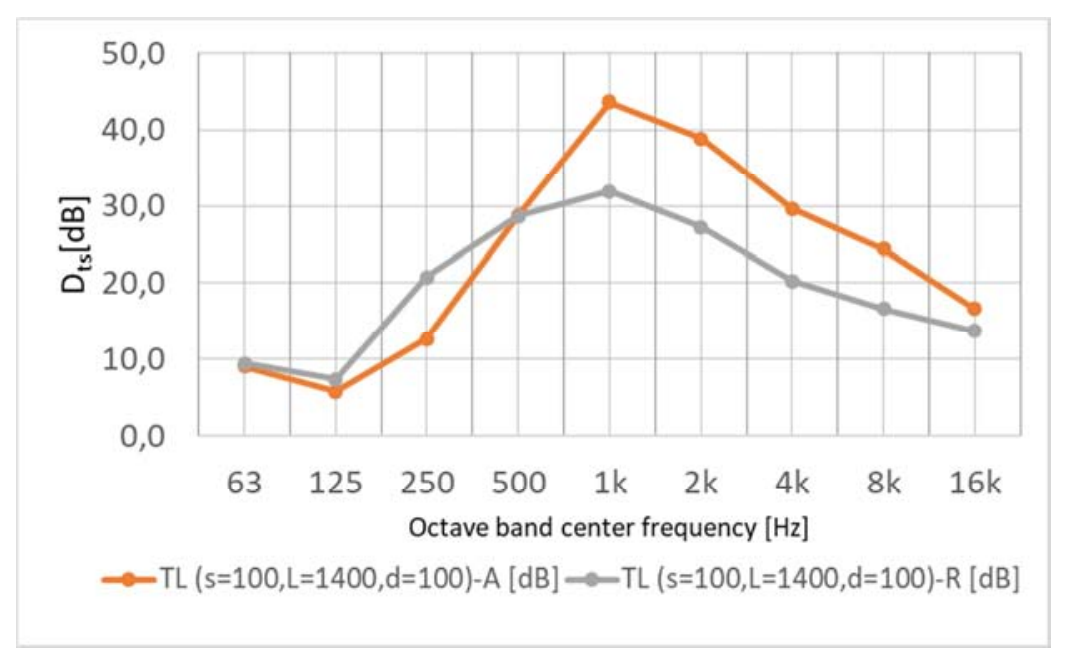




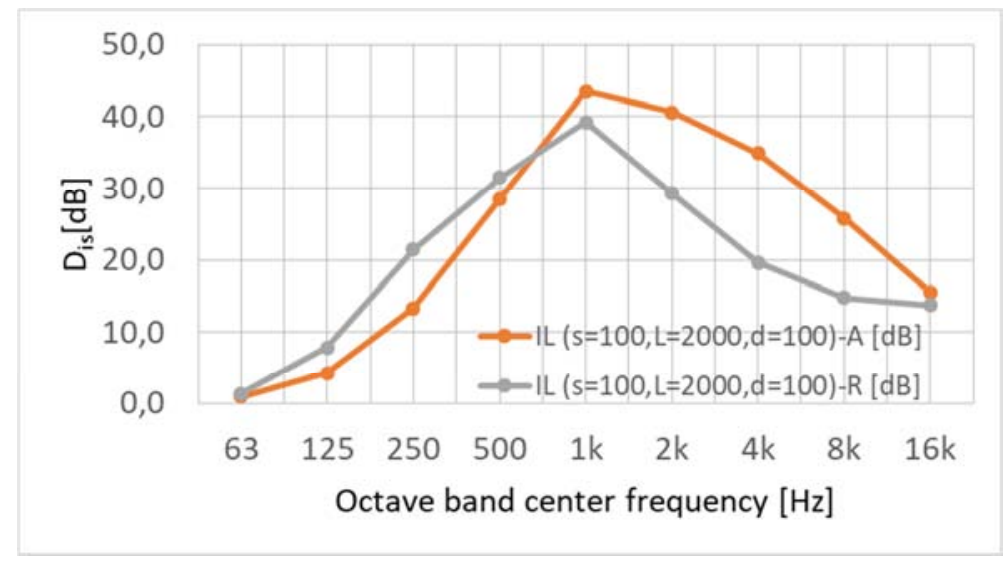

Figure 4. Comparison between absorptive and semi-reflective baffles performance.

\subsection{Comparison Between Artificial and Real Sound Source}

Additional measurements of i parameter have been done when the artificial sound source and real sound source (axial fan) giving the flow between baffles of $12 \mathrm{~m} / \mathrm{s}$. The results are shown in Figure 5.

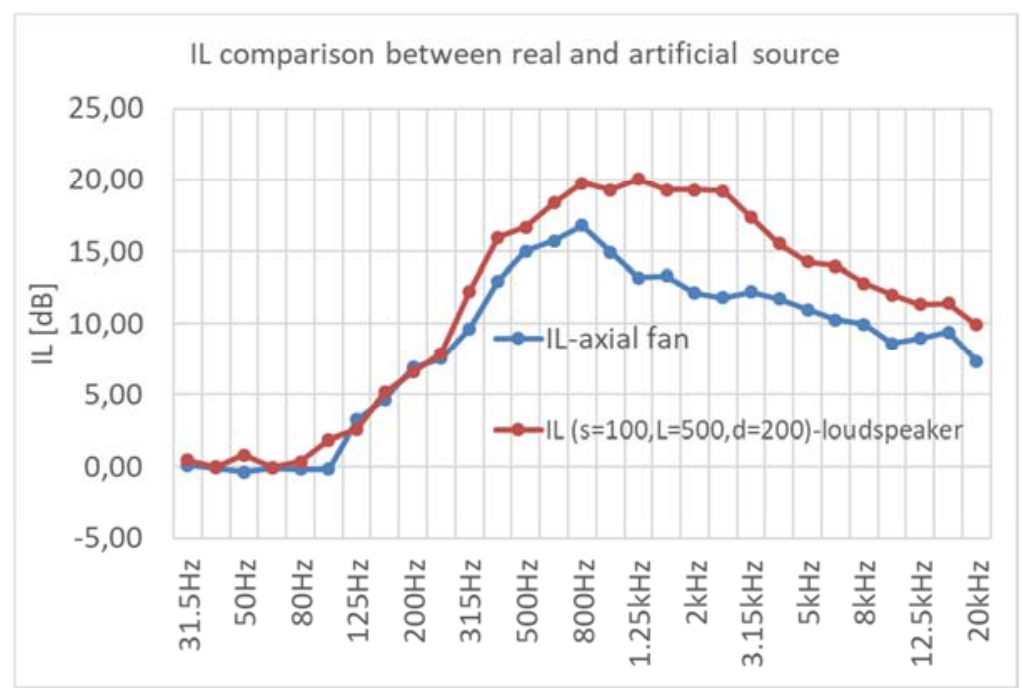

Figure 5. The comparison in performance when artificial and real sound source are used in measurements.

\subsection{Comparison in Performance When Space Between Baffles Is Added in the Direction of Propagation}

The long baffles with $L=2 \mathrm{~m}$ are replaced with two shorter baffles with $L=1 \mathrm{~m}$ and the difference in performance for $I L$ parameter is shown in Figure 6.

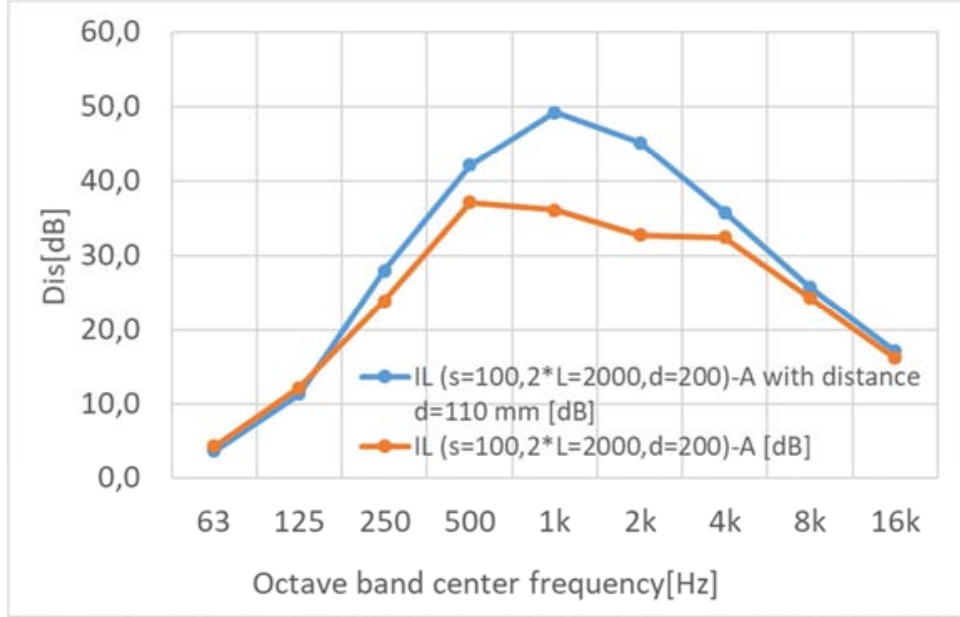




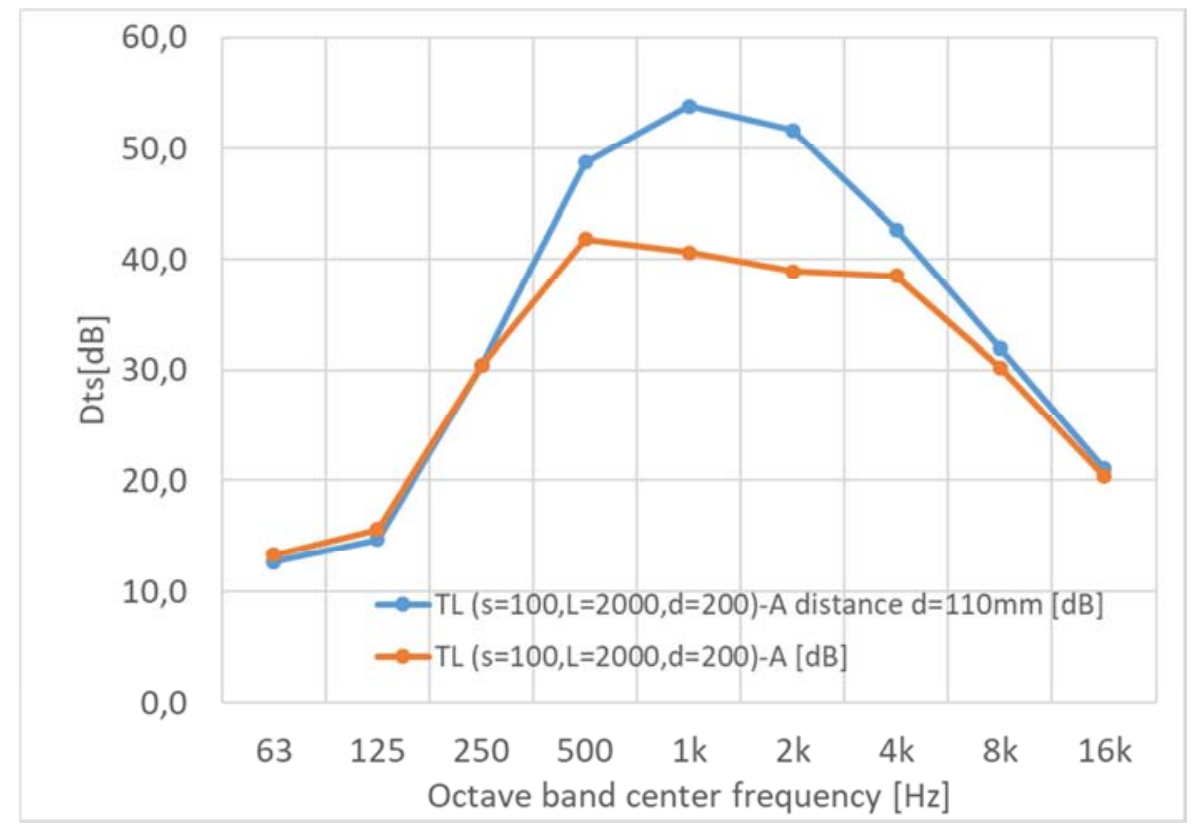

Figure 6. Comparison in the silencer performance when baffles with $L=2 \mathrm{~m}$ are replaced with two shorter baffles in direction of propagation.

\subsection{Comparison Between Measurement and Calculation Results}

The comparison between theoretical calculations according Piening and trapezoidal equation $[4,11,12]$ and measurement results for one configuration are shown in Figure 7.

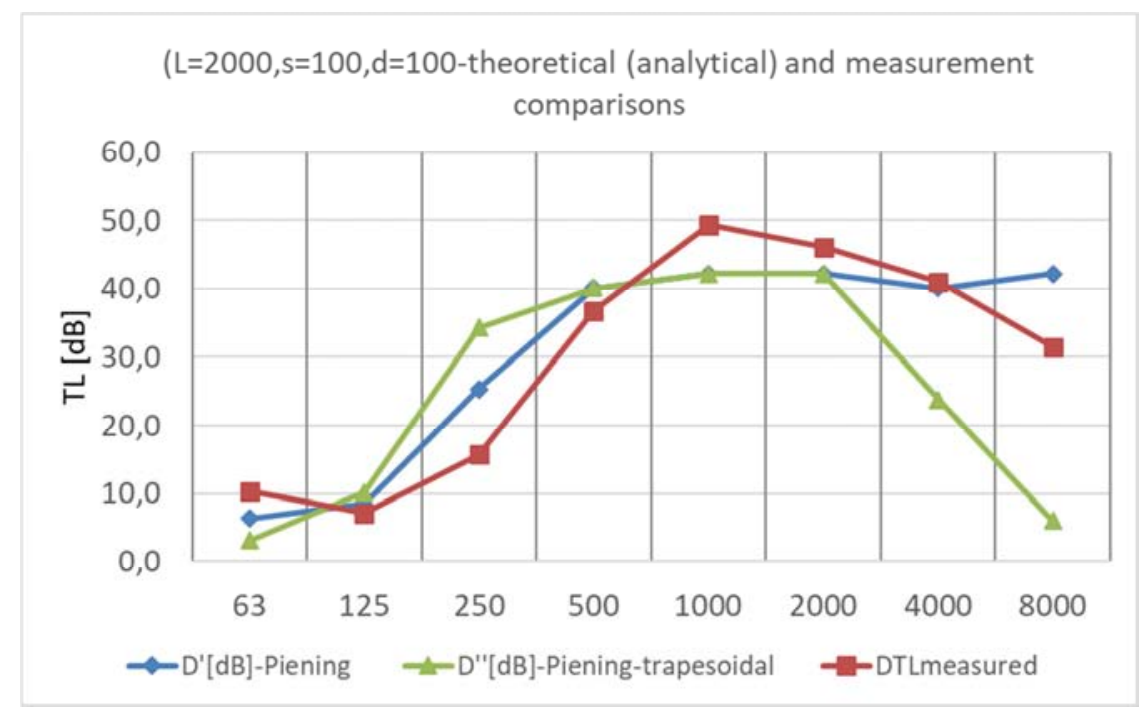

Figure 7. Comparison between analytical and measurement results for one configuration.

It is evident that there is a large difference for $T L$ parameter when measured and analytical results are compared. The cause for these difference is because of the influence of reflections in in-situ measurement setup on measured result (resonances at lower frequencies).

The analytical equations use assumption that absorption in baffles linearly depend vs length which is not obtained in measurements of SPL level between the baffles. The results for sound pressure distribution between baffles $(L=2000, s=200$, $d=300$ ) vs. distance from the beginning are shown in Figure 8. 

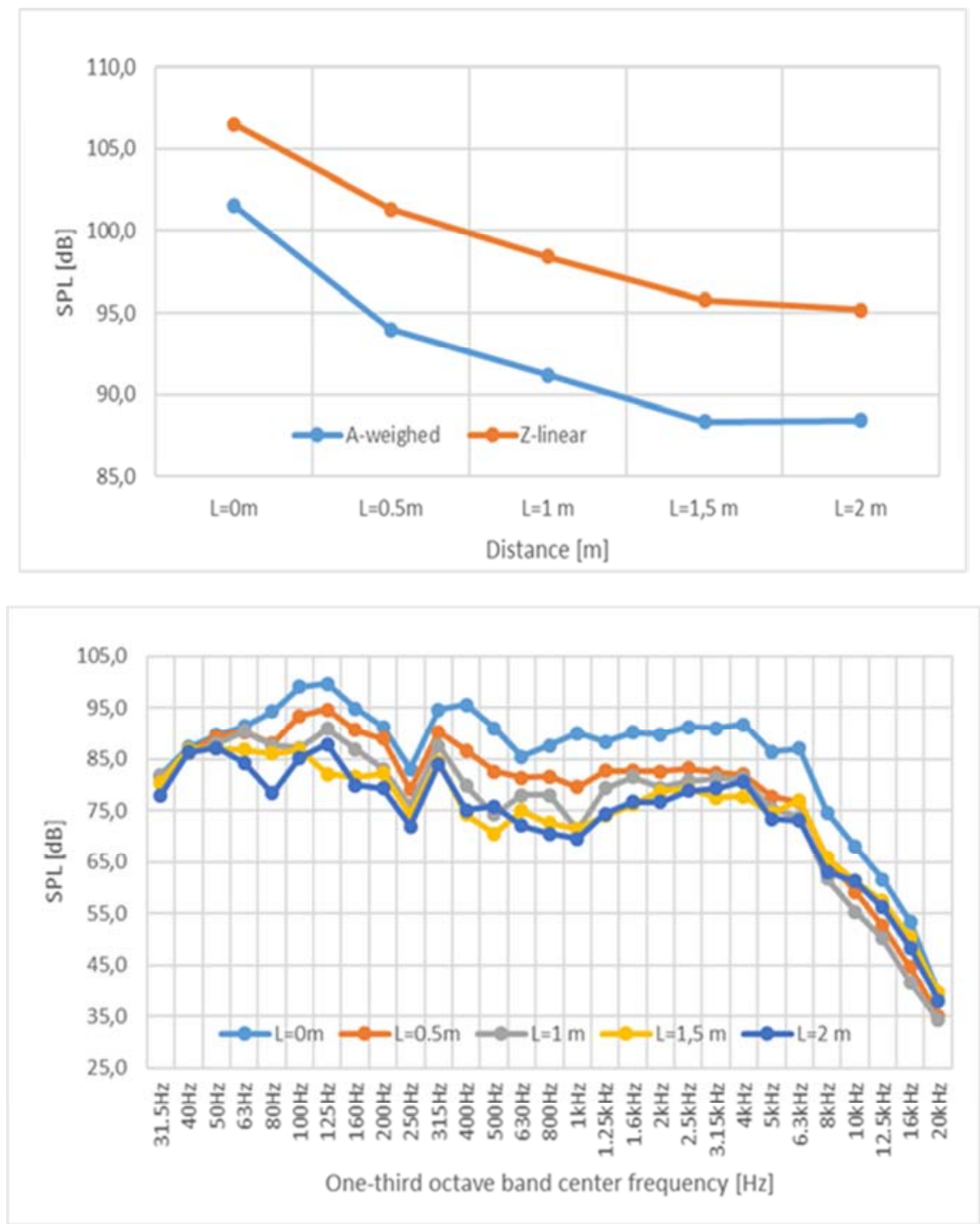

Figure 8. SPL distribution between central baffles (broadband and in one third octave bands of interest).

\subsection{Measurement Uncertainty}

The measurement uncertainty for this measurement method (coverage factor $k=2$, two side interval of conformity, $95 \%$ confidence level for two-sided test) for octave bands of interest are given in Table 8. The standard deviations are determined by measuring the averaged spatial pressure distributions ( 8 independent measurements in and outside the empty channel -standard deviation of repeatability). Measurement uncertainties are compared with those in reproducibility conditions given in ISO 3744:1994 Standard [13].

Table 8. The measurement uncertainty.

\begin{tabular}{llll}
\hline $\begin{array}{l}\text { Octave-band center } \\
\text { frequency [Hz] }\end{array}$ & $\begin{array}{l}\text { One-third-octave band center } \\
\text { frequency [Hz] }\end{array}$ & $\begin{array}{l}\text { Standard deviation of repeatability -from } \\
\text { measurements [dB] }\end{array}$ & $\begin{array}{l}\text { Standard deviation of } \\
\text { reproducibility [dB] }\end{array}$ \\
\hline 31.5 & $25-40$ & 1.6 & - \\
63 & $50-80$ & 1.5 & 5 \\
125 & $100-160$ & 1.6 & 3 \\
250 & $200-315$ & 1.6 & 2 \\
500 & $400-630$ & 1.5 & 1.5 \\
1000 & $800-1250$ & 1.5 & 1.5 \\
2000 & $1600-2500$ & 1.5 & 1.5 \\
4000 & $3150-5000$ & 1.5 & 1.5 \\
8000 & $6000-10000$ & 1.8 & 2.5 \\
16000 & $12500-20000$ & 2.0 & 2.5 \\
A-weighted & & 1.4 & 1.5 \\
Z-linear & & 1.2 & - \\
\hline
\end{tabular}




\section{Conclusion}

It is evident that $T L$ is higher few $\mathrm{dBs}$ in each octave band of interest due to reflections from baffles on inlet side (increased pressure level at inlet side for different configurations) and reflection from open end of the duct so the difference between sound pressure (power) is larger.

It is also evident, when baffles are longer than influence of space between baffles does not play significant role in silencer performance. The $T L$ parameter is higher at lower frequencies because resonance effects appear at inlet side due to reflection from baffles with small space between them.

The semi-reflective baffles are heavier when they are longer, so the performance is better at lower frequencies compared with absorptive baffles.

When real source is considered the parameters of silencer are lower at higher frequencies because self-noise appeared at higher frequencies and have significant influence on the performance.

The analytical calculation methods by using Piening and trapezoidal formula do not give satisfactory results because analytical equations assume linear dependence of $I L$ vs. length of silencer which is evidently not obtained with measurements. When SPL distribution between baffles is measured it is evident that at the beginning of the baffled channel the SPL gradient is much higher than at the end of baffled part of silencer.

In the future research the laboratory measurement setup will be used having purpose to reduce influence of reflections on measurement results.

\section{Acknowledgements}

This work has been supported by the European Union from European regional development fund (ERDF) under the project number KK.01.2.1.01.0103 Acoustical Camera (in Croatian: Akustička kamera).

\section{References}

[1] EN ISO 11820:1996, Acoustics- measurement of silencers in situ.

[2] ISO 7235-2003, EN ISO 7235:2009 Acoustics -- Laboratory measurement procedures for ducted silencers and air-terminal units -- Insertion loss, flow noise and total pressure loss.

[3] F. P. Mechel: Theory of baffle-type silencers. Acustica 70 (1990) 93-111.

[4] H. V. Fuchs: Schallabsorber und Schalldämpfer, Springer Verlag, 2010.

[5] M. L. Munjal: Acoustics of Ducts and Mufflers, 2nd Edition, 2014.

[6] David A. Bies, Colin H. Hansen: Engineering Noise Control: Theory and Practice, Fourth Edition, 2009.

[7] F. P. Mechel: Numerical results to the theory of baffle type silencers. Acustica 72 (1990) 7-20.

[8] A. Cummings and N. Sormaz: Acoustic attenuation in dissipative splitter silencers containing mean fluid flow. Journal of Sound and Vibration 168 (1993) 209-227.

[9] R. Kirby: The influence of baffle fairings on the acoustic performance of rectangular splitter silencers. J. Acoust. Soc. Am. 118 (2005) 2302-2312.

[10] R. Binois, E. Perrey-Debain, N. Dauchez, Benoit Nennig, J.-M. Ville, et al.: On the efficiency of parallel baffle-type silencers in rectangular ducts: prediction and measurement. Acta Acustica united with Acustica, Hirzel Verlag, 2015, 101, pp. 520-530.

[11] Helmut V. Fuchs: Grundlagen der SchalldämpferauslegungTeil 1: Vereinfachte Formeln für sichere Dimensionierung, IKZ-FACHPLANER Heft12/2007.

[12] VDI 2081:2001, Blatt1, Blatt2, Noise generation and noise reduction in air conditioning systems.

[13] ISO 3744:2011, Acoustics -- Determination of sound power levels and sound energy levels of noise sources using sound pressure -- Engineering methods for an essentially free field over a reflecting plane. 